\title{
DHPLC screening for mutations in progressive familial intrahepatic cholestasis patients
}

\author{
Rivka Shapiro $^{1,8}$, Yair Anikster ${ }^{2,8}$, Tal Yardeni ${ }^{3,8}$, Sigal Korem ${ }^{3,7}$, Korina Hartman ${ }^{1}$, Raanan Shamir ${ }^{1}$, \\ Efrat Broide $^{4}$, Arie Levine ${ }^{5}$, Yoram Bujanover ${ }^{6}$ and Dani Bercovich ${ }^{3,7}$
}

Progressive familial intrahepatic cholestasis (PFIC) is a group of rare heterogeneous autosomal recessive disorders characterized by metabolic defects in biliary proteins involved in the formation and transfer of bile acids in the liver. The genotype-phenotype correlation is not always clear. Mutations in the ATP8B1, BSEP and MDR3 genes have been associated with PFIC1, PFIC2 and PFIC3, respectively. This study sought to characterize the molecular genetic basis for PFIC subtypes in Israel. It was conducted on 14 children with PFIC and their families; 10 with a PFIC1 or PFIC2 phenotype and 4 with a PFIC3 phenotype. Using denaturing high-performance liquid chromatography (DHPLC), five different mutations were identified in four affected families: three novel mutations in BSEP (G19R-g181c, S226L-c803t and G877R-g2755a), one novel mutation in MDR3 (IVS14+6 t/c) and one heterozygous mutation in ATP8B1 (R600W, in a family with the PFIC1/PFIC2 phenotype). The cause of PFIC was identified in $20 \%$ of the families tested. These findings indicate the probable involvement of additional genes in PFIC and the need for further studies to determine whether the abnormality lies on the RNA or protein level. A better understanding of the phenotype-genotype correlation in PFIC will lead to improved diagnoses and treatments.

Journal of Human Genetics (2010) 55, 308-313; doi:10.1038/jhg.2010.28; published online 23 April 2010

Keywords: ATP8B1; BSEP; MDR3; mutation analysis; PFIC1; PFIC2; PFIC3

\section{INTRODUCTION}

Progressive familial intrahepatic cholestasis (PFIC) is a group of rare genetic heterogeneous autosomal recessive disorders characterized by defects in the biliary proteins involved in the formation and transfer of bile salts in the liver. ${ }^{1,2}$ The disease becomes evident in infancy, and without suitable treatment, may lead to death in the first decade of life. ${ }^{3}$ It is divided into three subtypes. The PFIC1 phenotype is caused by a variety of mutations in the ATP8B1 gene, which encodes for P-type adenosine triphosphatase (ATPase), a protein expressed in liver parenchymal cells and several organs. ${ }^{1}$ The protein probably functions as an aminophospholipid translocase and may have a role in the circulation of bile acids. ${ }^{2}$ PFIC2 is caused by mutations in the bile salt export pump (BSEP) gene (or ABCB11), which encodes for an ATPbinding cassette $(\mathrm{ABC})$ transporter protein that is expressed only in the canalicular membrane of the biliary tree and transfers bile salts from the liver to the gall bladder. ${ }^{4}$ PFIC 3 is caused by mutations in the MDR3 gene (or $A B C B 4$ ), which encodes for multidrug resistance P-glycoprotein, ${ }^{3}$ which is involved in the availability of phospholipids in the canalicular bile that help to organize the canaliculae and protect them from toxicity due to a high bile salt concentration. ${ }^{5}$ Defects in
MDR3, but not in ATP8B1 or BSEP, are associated with high levels of serum $\gamma$-glutamyltranspeptidase. ${ }^{4}$

The genotype-phenotype correlation in PFIC1 and PFIC2 is not always clear because of their considerable clinical overlap. ${ }^{6}$ Therefore, DNA screening for mutations in ATP8B1 and BSEP is usually necessary for diagnosis. ${ }^{3}$ The definitive treatment for PFIC is liver transplantation. ${ }^{7}$ Pharmacological treatments for the associated liver disease include (1) simvastatin (used in PFIC1), a hydroxymethyl glutamyl coenzyme A reductase inhibitor, which reduces the synthesis of bile acid from its precursor, cholesterol 2 and (2) ursodeoxycholic acid (used in PFIC3), which exerts a protective inhibitory effect on hepatocyte apoptosis by effecting a change in the arrangement of bile acid synthesis. ${ }^{8}$

The aims of this study were to characterize the molecular genetic basis of PFIC subtypes in Israel. We sought to identify mutations in the genes associated with the PFIC phenotypes and to screen for two additional candidate genes, farnesoid $\mathrm{X}$ receptor $(F X R)$ and $\mathrm{Na}$-dependent taurocholic co-transporting polypeptide (NTCP). The FXR gene, which encodes for a nuclear receptor involved in the regulation of $B S E P$ and $M D R 3,{ }^{9}$ is expressed in all tissues in which bile

\footnotetext{
${ }^{1}$ Institute of Gastroenterology, Schneider Children's Medical Center of Israel, Petach Tikva, Israel; ${ }^{2}$ Metabolic Disease Unit, Safra Children's Hospital, Sheba Medical Center, Tel Hashomer, Israel; ${ }^{3}$ Human Molecular Genetics and Pharmacogenetics, MIGAL-Galilee Technology Center, Kiryat-Shmona, Israel; ${ }^{4}$ Institute of Gastroenterology, Asaf Harofeh Medical Center, Tzrifin, Israel; ${ }^{5}$ Pediatric Gastroenterology Unit, Wolfson Medical Center, Holon, Israel; ${ }^{6}$ Pediatric Gastroenterology Unit, Sheba Medical Center, Tel Hashomer, Israel and ${ }^{7}$ Biotechnology Faculty, Tel-Hai Academic College, Tel Hai, Israel

8These authors contributed equally to this work.

Correspondence: Dr D Bercovich, Human Molecular Genetics and Pharmacogenetics, MIGAL_Galilee Technology Center, P0 Box 831, Kiryat-Shmona 11016, Israel. E-mail: danib@migal.org.il
}

Received 14 December 2009; revised 17 February 2010; accepted 10 March 2010; published online 23 April 2010 
salts are present. ${ }^{10}$ NTCP encodes for a transporter of bile salts to the liver. ${ }^{3}$ Both have been found to be expressed differently in patients with PFIC when compared with that in healthy controls.

\section{MATERIALS AND METHODS}

\section{Study group}

The study was conducted on 14 PFIC children and their families (including first-degree family members); 10 children with a PFIC1 or PFIC2 phenotype and 4 with a PFIC3 phenotype. All people participating in the study had given their informed consent before their inclusion in the study. Family histories were obtained by questioning the families/parents regarding any previous cases of neonatal jaundice, chronic liver diseases or liver transplantation in siblings. Of the 14 families, 11 were of Arabic (10 Muslim and one Druze) origin, and three were Jewish. All patients of Muslim origin were the outcome of consanguineous marriages, with parents being either first or second cousins. Among the Jewish patients, who were Ashkenazi (families 8,12 and 14), no consanguinity was found. The patients' backgrounds and laboratory findings are shown in Table 1.

This retrospective study uses the files of these 14 children who during the years 1998-2007 had been examined for chronic cholestasis, with elevated or normal $\gamma$-glutamyltranspeptidase. In the present investigation, subjects with infectious, autoimmune or metabolic diseases were ruled out. In all but two of the patients, a liver biopsy had been performed, which did not contribute to the diagnosis.

\section{DNA extraction and PCR amplification}

DNA was extracted from peripheral blood leukocytes according to standard protocols. All coding regions of the ATP8B1, BSEP and MDR3 genes and the intron/exon boundaries were amplified using sense and antisense oligonucleotides that were designed and numbered on the basis of the known sequence of the gene loci (GenBank accession numbers: NM_005603.3, NM_003742.2 and NM_018849.2, respectively). Amplifications were carried out by PCR in a total volume of $50 \mu \mathrm{l}$ with $10 \mathrm{~mm}$ Tris- $\mathrm{HCl}, \mathrm{pH} 8.3,1.5 \mathrm{~mm} \mathrm{MgCl}_{2}, 50 \mathrm{~mm} \mathrm{KCl}$, $0.2 \mathrm{~mm}$ deoxynucleotide triphosphates and $30 \mathrm{~nm}$ primers. The PCR conditions were $94{ }^{\circ} \mathrm{C}$ for $5 \mathrm{~min}$, followed by 35 cycles of $94^{\circ} \mathrm{C}$ for $30 \mathrm{~s}$, annealing temperatures for $1 \mathrm{~min}$ and $72^{\circ} \mathrm{C}$ for $1 \mathrm{~min}$, as described previously. ${ }^{11}$ The reactions were concluded with a final extension step of $72{ }^{\circ} \mathrm{C}$ for $7 \mathrm{~min}$. The primers, annealing temperatures and sizes of the PCR products for each of the 27 exons of ATP8B1, BSEP and MDR3 are available from the authors upon request. Patients with the PFIC1 or PFIC2 phenotypes were screened for $A T P 8 B 1$ and BSEP, and patients with the PFIC3 phenotype were examined for mutations in MDR3. When no mutations were identified, the coding regions of the two other candidates genes, FXR ( 9 exons) and NTCP (5 exons) (GenBank accession numbers: NM_005123.2 and NM_003049.2, respectively), were screened.

\section{Semiquantitative PCR}

Reactions were carried out in a total volume of $50 \mu \mathrm{l}$ with $10 \mathrm{~mm}$ Tris- $\mathrm{HCl}, \mathrm{pH}$ $8.3,1.5 \mathrm{mM} \mathrm{MgCl}_{2}, 50 \mathrm{~mm} \mathrm{KCl}, 0.2 \mathrm{~mm}$ deoxynucleotide triphosphates and $30 \mathrm{~nm}$ primers. The concentration of the DNA samples (from the suspected patient, and his mother as the control) was $50 \mathrm{ng}_{\mu} \mathrm{l}^{-1}$. The PCR conditions ${ }^{11}$ were $94{ }^{\circ} \mathrm{C}$ for $5 \mathrm{~min}$, followed by 24 cycles of $94^{\circ} \mathrm{C}$ for $0.5 \mathrm{~min}$ and annealing temperatures for $1 \mathrm{~min}$ and $72{ }^{\circ} \mathrm{C}$ for $1 \mathrm{~min}$. A final extension step of $72{ }^{\circ} \mathrm{C}$ for 7 min ended the PCR in the log stage. The exons assayed were exon 21 (359 bp)

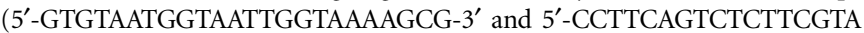
CTACTCG- $\left.3^{\prime}\right)$ in the BSEP gene and exon 14 (324bp) (5'-CTAAAATCCTA AGGTGGTTTTTGC- $3^{\prime}$ and $5^{\prime}$-ACAAAAAACCTGGTCTCTAATGCC- $3^{\prime}$ ) in the ATP8B1 gene, which served as the control.

\section{Denaturing high-performance liquid chromatography (DHPLC)} mutation screening

To scan for DNA mutations and variants using DHPLC, PCR products were subjected to chromatography using an ion-pair reversed-phase cartridge. The products were denatured and allowed to reanneal. Under conditions of partial denaturation with a linear acetonitrile gradient, heteroduplexes from PCR samples, which have an internal sequence variation, showed a reduced column retention time relative to their homoduplex counterparts. Because the elution profile for heterozygous samples is typically quite distinct from that of both homozygous sequences, the identification of heterozygous mutations was relatively straightforward. ${ }^{11}$ As required in homozygous autosomal mutations or in mutations on the $\mathrm{X}$ chromosome in males, the test sample was mixed with DNA of a known sequence. ${ }^{12}$

\section{Establishing DHPLC conditions}

Mutation analysis was performed using the WAVE apparatus (Transgenomic, Omaha, NE, USA). The PCR products were denatured at $95^{\circ} \mathrm{C}$ for $5 \mathrm{~min}$ and cooled to $65^{\circ} \mathrm{C}$, along a decreasing temperature gradient of $1^{\circ} \mathrm{C} \mathrm{min}^{-1}$. The

Table 1 Characterization of PFIC phenotypes

\begin{tabular}{|c|c|c|c|c|c|c|c|c|}
\hline Family no. & Sample no. & Sex & Age at diagnosis (years) & Consanguinity & $G G T$ & $L B x$ & $L T x$ & Outcome \\
\hline 1 & 1 & M & 4 & Y & 17 & Y & $\mathrm{N}$ & MR, FTT, CLD \\
\hline 2 & 3 & M & 0.8 & Y & 29 & Y & $\mathrm{N}$ & MR, FTT, CLD \\
\hline 3 & 5 & $M$ & 3 & Y & 27 & Y & Y & $A \& W$ \\
\hline 3 & 7 & M & 5 & Y & 17 & Y & Y & $A \& W$ \\
\hline 4 & 10 & M & 0.16 & $\mathrm{~N}$ & 32 & Y & $\mathrm{N}$ & $A, C L D$ \\
\hline 5 & 13 & $M$ & 0.3 & $\mathrm{~N}$ & 21 & $\mathrm{~N}$ & $\mathrm{~N}$ & $\mathrm{~A}, \mathrm{BD}, \mathrm{FTT}$ \\
\hline 5 & 14 & $M$ & 0.16 & Y & 20 & Y & Y & $A \& W$ \\
\hline 6 & 17 & $M$ & 0.3 & $\mathrm{~N}$ & 25 & $\mathrm{~N}$ & $\mathrm{~N}$ & $A, C L D$, severe $M R$ \\
\hline 7 & 31 & $\mathrm{~F}$ & 0.1 & $\mathrm{~N}$ & 24 & Y & $\mathrm{N}$ & $\mathrm{BD}$, healthy \\
\hline 7 & 32 & $\mathrm{~F}$ & 0.05 & $\mathrm{~N}$ & 28 & Y & $\mathrm{N}$ & $\mathrm{BD}$, mild choles \\
\hline 8 & 34 & M & 0.08 & $Y$ & 36 & Y & Y & $A \& W$ \\
\hline 9 & 41 & $\mathrm{~F}$ & 14 & $\mathrm{~N}$ & 6 & Y & $\mathrm{N}$ & $A \& W$ \\
\hline 10 & 46 & - & - & - & - & - & - & - \\
\hline 11 & 20 & M & 0.75 & Y & 520 & Y & YX4 & Death \\
\hline 12 & 23 & $\mathrm{~F}$ & - & - & - & $\mathrm{N}$ & - & - \\
\hline 13 & 28 & $\mathrm{~F}$ & 0.2 & $\mathrm{~N}$ & 1456 & $Y$ & $\mathrm{~N}$ & BD, choles \\
\hline 14 & 36 & $M$ & 1 & $\mathrm{~N}$ & 156 & $Y$ & $\mathrm{~N}$ & Death, HCC \\
\hline 14 & 39 & M & 0.41 & $\mathrm{~N}$ & 107 & Y & $\mathrm{N}$ & $A$ and CLD \\
\hline
\end{tabular}

Abbreviations: A, alive; A\&W, alive and well; BD, biliary diversion; Choles, cholestasis; CLD, chronic liver disease; F, female; FT, failure to thrive; GGT, $\gamma$-glutamyl transferase; HCC, hepatocellular carcinoma; LBx, liver biopsy; LTx, liver transplantation; M, male; MR, mental retardation; N, no; PFIC, progressive familial intrahepatic cholestasis; Y, yes. 
samples were kept at $4{ }^{\circ} \mathrm{C}$ until $5 \mu$ was applied to a preheated C18 reversedphase column, based on nonporous particles (polystyrene-divinyl-benzene) (DNA-Sep Cartridge, cat. no. 450181; Transgenomic). DNA was eluted within a linear acetonitrile gradient, consisting of buffer A $(0.1 \mathrm{~m}$ triethylammonium acetate, cat. no. SP5890; Transgenomic))/buffer B (0.1 M triethylammonium acetate, $25 \%$ acetonitrile, cat. no. 700001 ; Transgenomic)]. The temperature at which heteroduplex detection occurred was deduced by the Transgenomic software (Wavemaker 4.2) and the Stanford DHPLC melting program (http:// insertion.stanford.edu/meltdoc.html), which analyzes the melting profile of each specific DNA fragment.

\section{Linkage analysis}

The single-nucleotide polymorphisms (SNPs) that were selected for linkage analysis were established SNPs (HapMap and NCBI (National Center for Biotechnology Information) database, http://www.ncbi.nlm.nih.gov/), which have high heterozygote frequencies $(<30 \%)$ in the relevant ethnic group. Primers were designed accordingly. According to SNPs of DNA samples from patients and their parents, if available, the allelic pattern inherited in the family was defined to determine whether this genomic region was involved in these phenotypes. The SNP NCBI association numbers are as follows: for BSEP-rs3814381, rs478333, rs3770598, rs6759156, rs2892809, rs555975, rs503931, rs2685814, rs2241339, rs2058996, rs1101533 and rs853779; for MDR3-rs1526090, rs12154399, rs4148830, rs31667, rs31670, rs31674, rs31676, rs1558376, rs4148816 and rs4148809; and for FXR-rs12297839, rs7304328, rs2148670, rs2303624, rs11110414, rs10860603, rs35735, rs11110411 and rs7960489.

\section{Homozygous mutation screening}

To identify homozygous mutations, $10 \mu$ of each PCR product from wild-type DNA and $10 \mu \mathrm{l}$ of the PCR product of sample DNA were mixed 1:1 and denatured at $95^{\circ} \mathrm{C}$. The formation of heteroduplexes indicated homozygosity. ${ }^{12}$

\section{DNA sequencing}

DNA sequencing was performed on the PCR products after DHPLC analysis, as previously described. ${ }^{11}$ Reamplified PCR products (forward and reverse) with an abnormal DHPLC pattern were subjected to sequence analysis by an ABI PRISM 3100 Genetic analyzer (PE Biosystems, Foster City, CA, USA), according to the manufacturer's protocol. Nucleotide numbering was in accordance with the GenBank database of nucleotide sequences (accession numbers NM_005603.3, NM_003742.2, NM_018849.2, NM_005123.2 and NM_005123.2).

\section{RESULTS}

The findings of the genetic analysis are shown in Table 2. For the firstline assessment, the entire coding region of ATP8B1, the first gene discovered to be involved in PFIC $1,{ }^{13}$ was screened. From this, only one heterozygous mutation (R600W) was identified, and it was in family. ${ }^{9}$ This mutation is known to have a role in benign recurrent intrahepatic cholestasis. ${ }^{14}$

Subsequently, linkage analysis was conducted on the BSEP gene. The SNP haplotype (TTCC) was found in two patients from family 3 , but not in their healthy sibling (Figure 1), implying a DNA alteration in the region related to the PFIC2 phenotype. Screening this family's DNA yielded two novel heterozygous mutations in BSEP (G19R-g181c and S226L-c803t). Each of the mutant alleles was inherited from one of the parents (that is, the children were probably compound heterozygotes; Figure 2).

In other families in which the linkage study was not informative, the entire gene was screened. Family 2 was found to harbor a novel mutation, G877R-g2755a, in a homozygous state (Figure 3). The mother of this family was a carrier, and the paternal DNA was not available for analysis. As the patient was found to be homozygous for all SNPs in the screened gene, semiquantitative PCR analysis was used in an attempt to determine whether the mutation was
Table 2 Results from the screening of the five candidate genes

\begin{tabular}{|c|c|c|c|c|c|c|}
\hline Family & $D N A$ & ATP8B1 & $B S E P$ & MDR3 & $F X R$ & NTCP \\
\hline \multirow[t]{2}{*}{1} & 1-patient & WT & WT & - & WT & WT \\
\hline & $1-\mathrm{M}$ & WT & WT & - & WT & WT \\
\hline \multirow[t]{2}{*}{2} & 2-patient & WT & G877R & - & WT & WT \\
\hline & $2-M$ & WT & G877R/N & - & WT & WT \\
\hline \multirow[t]{5}{*}{3} & 3-patient & WT & G19R/N; S226L/N & - & WT & WT \\
\hline & 3-B & WT & $\mathrm{S} 226 \mathrm{~L} / \mathrm{N}$ & - & WT & WT \\
\hline & 3-patient & WT & G19R/N; S226L/N & - & WT & WT \\
\hline & $3-M$ & WT & S226L/N & - & WT & WT \\
\hline & $3-\mathrm{F}$ & WT & G19R/N & - & WT & WT \\
\hline \multirow[t]{3}{*}{4} & 4-patient & WT & WT & - & WT & WT \\
\hline & $4-M$ & WT & WT & - & WT & WT \\
\hline & $4-B$ & WT & WT & - & WT & WT \\
\hline \multirow[t]{4}{*}{5} & 5-patient & W.T & WT & - & WT & WT \\
\hline & 5-patient & WT & WT & - & WT & WT \\
\hline & $5-M$ & WT & WT & - & WT & WT \\
\hline & $5-\mathrm{F}$ & WT & WT & - & WT & WT \\
\hline \multirow[t]{3}{*}{6} & 6-patient & WT & WT & - & WT & WT \\
\hline & $6-M$ & WT & WT & - & WT & WT \\
\hline & $6-\mathrm{F}$ & WT & WT & - & WT & WT \\
\hline \multirow[t]{3}{*}{7} & 7-patient & WT & WT & - & WT & WT \\
\hline & 7-patient & WT & WT & - & WT & WT \\
\hline & 7-M & WT & WT & - & WT & WT \\
\hline \multirow[t]{2}{*}{8} & 8-patient & WT & WT & - & WT & WT \\
\hline & $8-M$ & WT & WT & - & WT & WT \\
\hline \multirow[t]{5}{*}{9} & 9-patient & R600W/N & WT & - & WT & WT \\
\hline & $9-\mathrm{F}$ & WT & WT & - & WT & WT \\
\hline & $9-M$ & R600W/N & WT & - & WT & WT \\
\hline & 9-S & R600W/N & WT & - & WT & WT \\
\hline & 9-S & WT & WT & - & WT & WT \\
\hline \multirow[t]{2}{*}{10} & 10-patient & WT & WT & - & WT & WT \\
\hline & $10-\mathrm{F}$ & WT & WT & - & WT & WT \\
\hline \multirow[t]{3}{*}{11} & 11-patient & - & - & WT & WT & - \\
\hline & $11-\mathrm{M}$ & - & - & WT & WT & - \\
\hline & $11-\mathrm{F}$ & - & - & WT & WT & - \\
\hline \multirow[t]{2}{*}{12} & 12-patient & - & - & IVS14+6t/c/N & WT & - \\
\hline & $12-\mathrm{F}$ & - & - & W.T & WT & - \\
\hline \multirow[t]{3}{*}{13} & 13-patient & - & - & WT & WT & - \\
\hline & $13-\mathrm{M}$ & - & - & WT & WT & - \\
\hline & $13-\mathrm{F}$ & - & - & WT & WT & - \\
\hline \multirow[t]{5}{*}{14} & 14-patient & - & - & WT & WT & - \\
\hline & $14-\mathrm{M}$ & - & - & WT & WT & - \\
\hline & $14-\mathrm{F}$ & - & - & WT & WT & - \\
\hline & $14-B$ & - & - & WT & WT & - \\
\hline & $14-S$ & - & - & WT & WT & - \\
\hline
\end{tabular}

Abbreviations: $\mathrm{B}$, brother; BSEP, bile salt export pump; $\mathrm{F}$, father; FXR, farnesoid $\mathrm{X}$ receptor; $\mathrm{M}$, mother; NTCP, Na+-dependent taurocholic co-transporting polypeptide; S, sister; WT, wild type.

hemizygous (that is, one mutated allele and one deleted allele). Results of this analysis, which compared the relative quantity of the $B S E P$ alleles in the maternal and patient DNA (Figures $4 \mathrm{a}$ and $\mathrm{b}$ ), revealed that the mutation was present in the hemizygous state in the patient.

Linkage analysis was performed on DNA from three of the four families with PFIC3 (family 12 was not tested because the maternal DNA was unavailable). No association with the MDR3 gene was found in family 14 , but its involvement in families 11 and 13 could not be ruled out. In addition, DNA screening for MDR3 mutations in families 11, 12 and 13 yielded one heterozygous novel splice-site 
mutation (IVS14+6 t/c) in the patient from family 12 . The origin of the mutation could not be proven, as only DNA from the father, who did not harbor the mutation, was available. No other mutations were

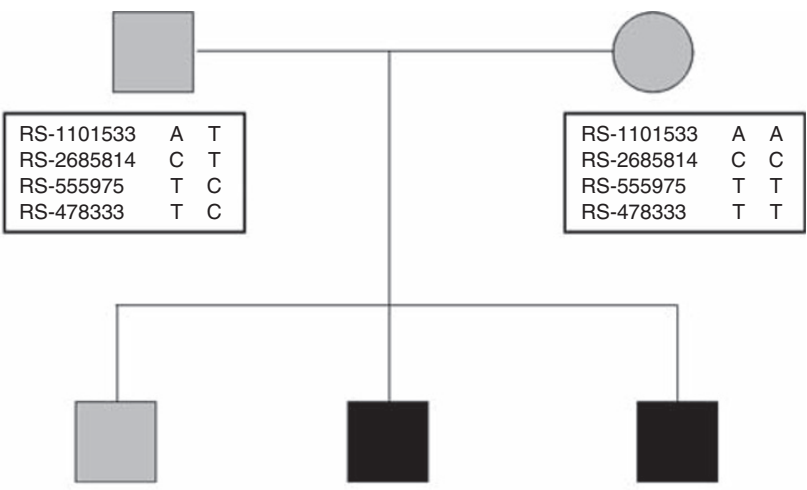

RS-1101533 A A

RS-2685814 C $\quad$ C

RS-555975 T T

RS-478333

$\begin{array}{ll}\mathrm{T} & \mathrm{T} \\ \mathrm{T} & \mathrm{T}\end{array}$

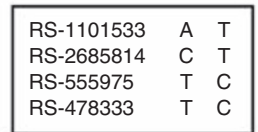

RS-1101533 A T RS-2685814 C T RS-555975 T $\begin{array}{lll}\text { RS }-478333 & \text { T } & \text { C }\end{array}$

Figure 1 Structure of allele segregation in family 3 according to SNPs in $B S E P$ gene. Black, patient; gray, carrier. SNP genotypes appear in the boxes.

identified in the remaining coding and promoter regions of the MDR3 gene in this patient.

Linkage analysis and mutation screening of the two suggested candidate genes, FXR and NTCP, produced only negative results.

In total, five mutations were discovered in the $A T P 8 B, B S E P$ and MDR3 genes; that is, three novel mutations in BSEP (G19R-g181c, S226L-c803t and G877R-g2755a), one novel mutation in MDR3 (IVS14+6 t/c) and only one heterozygous mutation in ATP8B1 (R600W).

\section{DISCUSSION}

In this study, the genetic cause of PFIC1/PFIC2 was identified in 2 of 14 children (10 families). The patients from family 3 were compound heterozygotes for two mutations in BSEP-G19R and S226L-and the patient from family 2 had a hemizygous mutation in BSEP-G877R. S226L and G877R are missense mutations at the conserved and active sites of the proteins (ConSeq; http://conseq.tau.ac.il; Figure 5), and G19R is located at the N-terminal region of the BSEP protein. In another family with PFIC1/PFIC2 (family 9), one missense mutation was found in ATP8B1 (R600W). However, it could not account for the phenotype. The same mutation has been reported previously in a patient with benign recurrent intrahepatic cholestasis. ${ }^{15}$ However, unlike PFIC, benign recurrent intrahepatic cholestasis has a mild phenotype, as the ATP8B1 mutations associated with the disease do not have a deleterious effect on protein function.

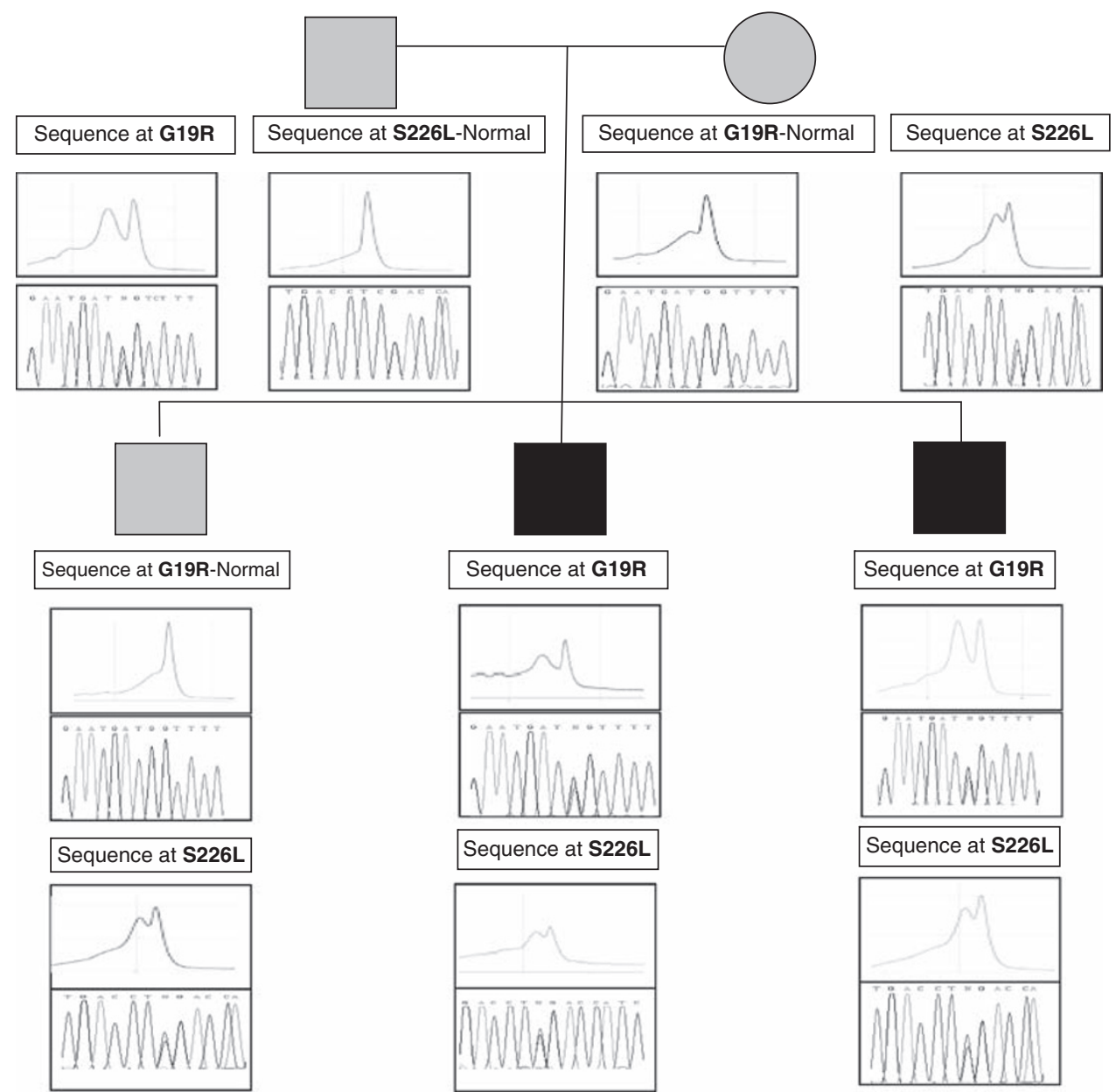

Figure 2 DHPLC analysis and sequence of mutations in family 3. There are two different heterozygous mutations in the BSEP gene. The patients inherited each mutant allele from a different parent, black, patient; gray, carrier. Mutations detected by the DHPLC are shown in the upper figure and their sequences are in the lower figure. 

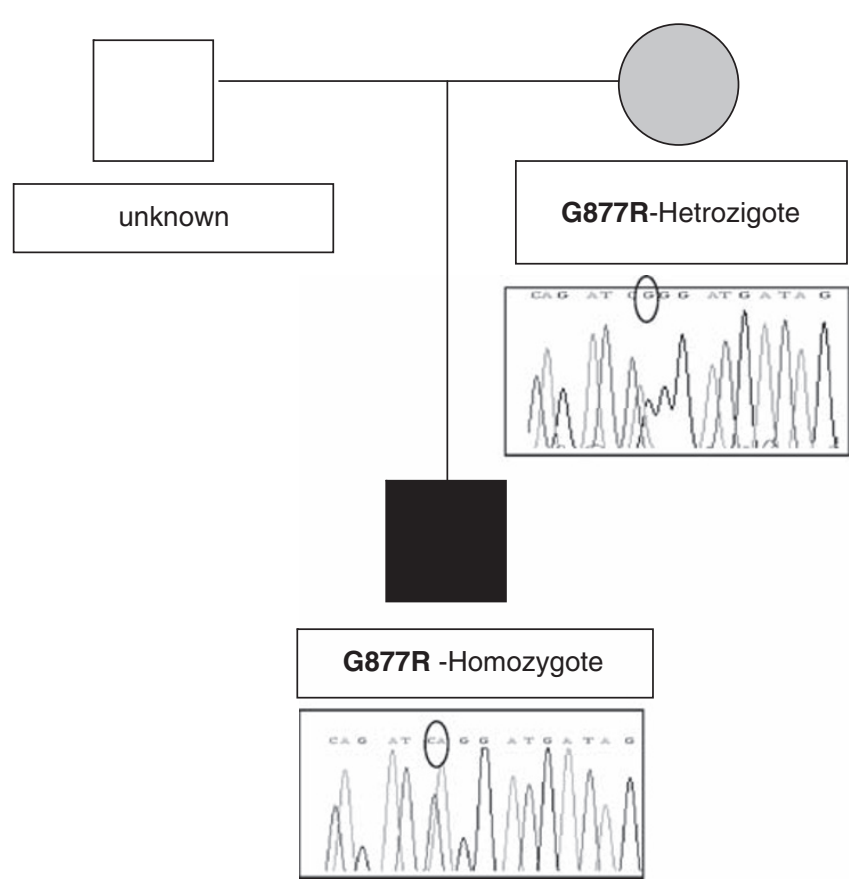

Figure 3 Sequence analysis of the G877R $(2755 \mathrm{~g}>\mathrm{a})$ missense mutations of the BSEP gene in family 2. Only the DNA samples of the female patient and her healthy mother were available for screening. The mother was found to be heterozygous and the daughter hemizygous for this mutation.

These mutations were compared with those discovered in other populations, but four out of five were not found. The mutation R600W was sited in one rare case (adult patient) in Taiwan. All of these families (2,3 and 9) were of Muslim origin, and the patients were the result of consanguineous marriages, with parents being either first or second cousins. As these mutations have not been reported previously, they could not be compared with other ethnic groups.

In family 12, with the PFIC3 phenotype, one heterozygous mutation was discovered on the MDR3 gene of the patient. However, alone, it could not be the reason for the disease. It is possible that there is another heterozygous mutation in a control region that was not discerned. None of these five mutations were detected in the screening of 200 alleles in DNA control samples.

The screening of the two candidate genes, FXR and NTCP, known to be involved in bile acid homeostasis in the liver 7 , yielded no mutations.

PFIC is a heterogeneous disease, and it is likely that other unknown genes are involved. Clinical criteria alone are not enough to identify the molecular defects in PFIC2, and genetic screening is the best method to differentiate PFIC2 from PFIC1 4. Because of its grave prognosis 3, genetic counseling and prenatal diagnosis are recommended in affected families.

In the present study, by combining the clinical diagnosis of PFIC with the screening of suspected genes by DNA chromatography and direct sequencing, we were able to identify the causes of the disease in $20 \%$ of the families tested. All analyses were carried out on the DNA level, as liver biopsies were not available. Further studies on the RNA and protein level are required to determine whether the abnormalities lie in gene expression or gene translation.

Our results point out the heterogeneity of PFIC, and hopefully the new genetic technology that has emerged recently will help to elucidate the $80 \%$ unsolved cases. For example, homozygosis mapping

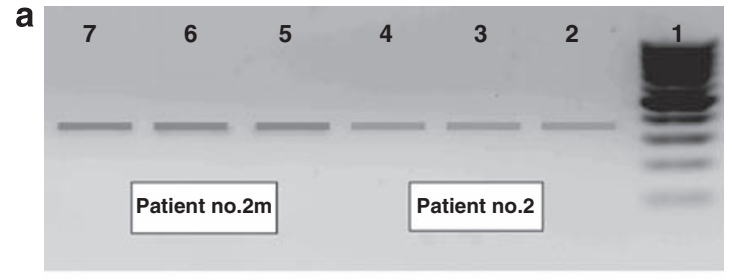

ATP8B1gene chromosome 18 ex14 (324bp)
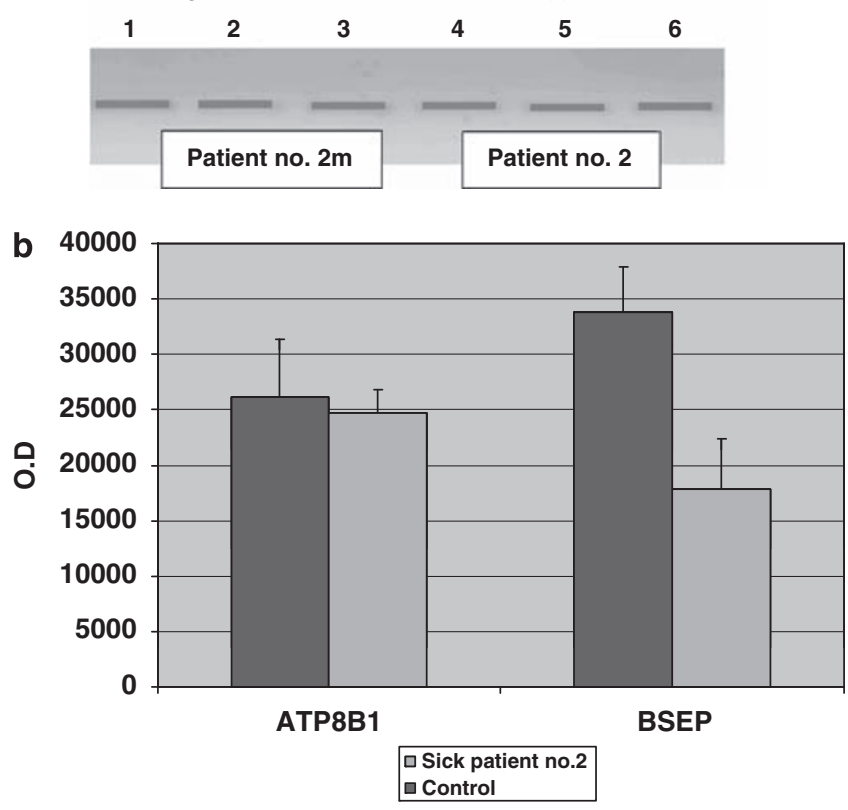

Figure 4 The semiquantitative PCR analysis of the BSEP and control genes (ATP8B1) in family 2 (patient and his mother). (a) Gels and (b) graph of the optical density ratio between the BSEP and the ATP8B1 PCR products. The patient/mother DNA concentration ratio was 0.94 for ATP8B1 (control) and 0.52 for BSEP.

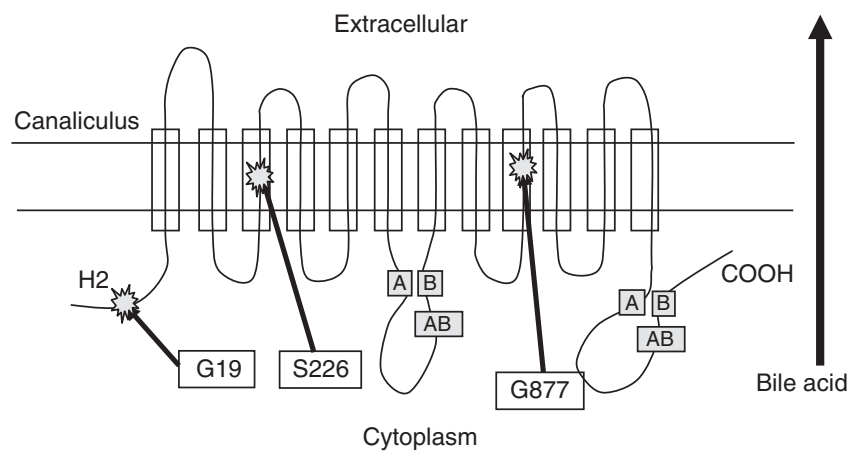

Figure 5 Schematic representation of the BSEP gene structure and the mutation locations. BSEP is a transmembrane protein that crosses the membrane 12 times. It has two domains of the ATP-binding cassette (ABC) transporters (green). The two mutations (S226L and G877R) are in the functional regions of the protein. One mutation (G19R) is in the N-terminal region. A full color version of this figure is available at the Journal of Human Genetics journal online.

of many of our families may provide the first clue regarding the region of a new locus for PFIC. A better understanding of the genotypephenotype correlation in PFIC will improve diagnoses and treatments of this disease. 


\section{CONFLICT OF INTEREST}

The authors declare no conflict of interest.

\section{ACKNOWLEDGEMENTS}

This study was supported in part by grants from the Israel Ministry of Health, and it partially fulfills the requirements for the Master's Degree at Tel Aviv University of Tal Yardeni. We thank the Israeli PFIC families for their cooperation.

1 Jung, C., Driancourt, C., Baussan, C., Zater, M., Hadchouel, M., Meunier-Rotival, M. et al. Prenatal molecular diagnosis of inherited cholestatic diseases. J. Pediatr. Gastroenterol. Nutr. 44, 453-458 (2007).

2 Kubitz, R., Keitel, V. \& Haussinger, D. Inborn errors of biliary canalicular transport systems. Methods Enzymol. 400, 558-569 (2005).

3 Jansen, P. L. \& Sturm, E. Genetic cholestasis, causes and consequences for hepatobiliary transport. Liver Int. 23, 315-322 (2003).

4 Nobili, V., Di Giandomenico, S., Francalanci, P., Callea, F., Marcellini, M. \& Santorelli, F. M. A new $A B C B 11$ mutation in two Italian children with familial intrahepatic cholestasis. J. Gastroenterol. 41, 598-603 (2006).

5 Dixon, P. H., Weerasekera, N., Linton, K. J., Donaldson, O., Chambers, J., Egginton, E. et al. Heterozygous MDR3 missense mutation associated with intrahepatic cholestasis of pregnancy: evidence for a defect in protein trafficking. Hum. Mol. Genet. 9, 1209-1217 (2000)
6 Keitel, V., Burdelski, M., Warskulat, U., Kuhlkamp, T., Keppler, D., Haussinger, D. et al. Expression and localization of hepatobiliary transport proteins in progressive familial intrahepatic cholestasis. Hepatology 41, 1160-1172 (2005).

7 Trauner, M. \& Boyer, J. L. Bile salt transporters: molecular characterization, function, and regulation. Physiol. Rev. 83, 633-671 (2003).

8 Jacquemin, E. Progressive familial intrahepatic cholestasis. J. Gastroenterol. Hepatol. 14, 594-599 (1999).

9 Wang, L., Soroka, C. J. \& Boyer, J. L. The role of bile salt export pump mutations in progressive familial intrahepatic cholestasis type II. J. Clin. Invest. 110, 965-972 (2002).

10 Paulusma, C. C. \& Oude Elferink, R. P. The type 4 subfamily of P-type ATPases, putative aminophospholipid translocases with a role in human disease. Biochim. Biophys. Acta. 1741, 11-24 (2005).

11 Bercovich, D. \& Beaudet, A. L. Denaturing high-performance liquid chromatography for the detection of mutations and polymorphisms in UBE3A. Genet. Test. 7, 189-194 (2003).

12 Shlush, L. I., Behar, D. M., Zelazny, A., Keller, N., Lupski, J. R., Beaudet, A. L. et al. Molecular epidemiological analysis of the changing nature of a meningococcal outbreak following a vaccination campaign. J. Clin. Microbiol. 40, 3565-3571 (2002).

13 Clayton, R. J., Iber, F. L., Ruebner, B. H. \& McKusick, V. A. Byler disease. Fatal familial intrahepatic cholestasis in an Amish kindred. Am. J. Dis. Child. 117, 112-124 (1969).

14 Klomp, L. W., Vargas, J. C., van Mil, S. W., Pawlikowska, L., Strautnieks, S. S., van Eijk, M. J. et al. Characterization of mutations in ATP8B1 associated with hereditary cholestasis. Hepatology 40, 27-38 (2004).

15 O'Leary, J. G. \& Pratt, D. S. Cholestasis and cholestatic syndromes. Curr. Opin. Gastroenterol. 23, 232-236 (2007). 